\title{
EDUTECH
}

\section{TECHNOLOGICAL PEDAGOGICAL CONTENT KNOWLEDGE (TPACK) DALAM RANGKA PENINGKATAN KUALITAS PEMBELAJARAN MAHASISWA PPG SD PRAJABATAN}

\section{Tatat Hartati, Dwi Heryanto, Nuri Annisa, Risma Nuriyanti, Alpin Herman Saputra, Rahmat Sutedi Universitas Pendidikan Indonesia}

Email : tatat@upi.edu,dwi_heryanto@upi.edu,nuriannisaupi@gmail.com,nuriyantirisma@upi.edu, alpinherman@gmail.com, sutedirahmat91@gmail.com

\begin{abstract}
The quality of learning carried out by an educator has not yet received serious attention. This has an impact on the low quality of graduates produced. The core research aims to develop and implement Technology Pedagogical Content Knowledge (TPACK) for participants of the Pre-Service Professional Educational Program (PPG). The method used is a quantitative approach. The subjects in this study were 42 students of Pre-Service Professional Educational Program students who were divided into control and experimental classes. 21 students each. The results of this study are in the form of a literacy and high-level TPACK-based TPACK model and the results of the pretest and posttest scores with a significance value of 0.001 which can be concluded that the TPACK-based literacy model and high-level thinking abilities influence the learning quality of Pre-Service Professional Educational Program students.
\end{abstract}

Informasi Artikel :

Artikel diterima 24 Januari 2019

Perbaikan 16 Maret 2019

Diterbitkan 15 Juni 2019

Terbit Online 26 Juni 2019

Kata kunci: TPACK, PPG, Learning Quality

\section{A. PENDAHULUAN}

Kualitas pembelajaran merupakan salah satu unsur dari paradigma baru pengelolaan pendidikan tinggi di Indonesia yang sangat penting dimiliki baik oleh seorang guru maupun seorang calon guru. Paradigma tersebut mengandung atribut pokok, yaitu relevan dengan kebutuhan masyarakat dan pengguna lulusan, memiliki suasana akademik (academic-atmospehere) dalam penyelenggaraan program studi, adanya komitmen kelembagaan (institutional commitment) dari para pimpinan dan staf terhadap pengelolaan organisasi yang efektif dan produktif, keberlanjutan (sustainability) program studi, serta efisiensi program secara selektif berdasarkan kelayakan dan kecukupan.

Dimensi-dimensi tersebut mempunyai kedudukan dan fungsi yang sangat strategis untuk merancang dan mengembangkan usaha penyelenggaraan pendidikan yang berorientasi kualitas pada masa yang akan datang. Kualitas pembelajaran sangat identik dengan bagaimana seorang pendidik mengemas pembelajaran sesuai dengan materi pembelajaran dan karakteristik siswa (Seknun, 2014). Namun pada era revolusi industri 4.0 seorang guru dituntut tidak hanya memberikan pembelajaran yang sesuai dengan kurikulum akan tetapi dapat mening- 
175 Technological Pedagogical Content Knowledge (TPACK) Dalam Rangka Peningkatan Kualitas Pembelajaran Mahasiswa PPG SD Prajabatan

katkan kemampuan literasi dan kemampuan berpikir tingkat tinggi siswa (Muhali, 2018).

Peningkatan kualitas pendidikan dapat ditempuh dengan berbagai cara, antara lain peningkatan kompetensi guru dan calon guru, perubahan kurikulum, peningkatan kualitas pembelajaran dan penilaian, penyediaan bahan ajar, serta tersedianya sarana dan prasarana yang memadai. Dari semua cara tersebut, peningkatan kompetensi guru/ calon guru merupakan hal yang sangat krusial, mengingat guru merupakan ujung tombak dalam pembelajaran. Seorang guru dituntut memiliki pengetahuan tentang bagaimana mengajarkan suatu materi ajar kepada muridnya dengan cara mengintegrasikan pengetahuan konten dengan kurikulum, dengan pembelajaran, dengan karakteristik siswa. Sebelum mengkaji TPACK, terlebih dahulu akan dipaparkan mengenai PCK (Pedagogical Content Knowledge).

Gabungan pengetahuan isi/materi dengan pengetahuan pedagogi inilah yang oleh Shulman (1986) \& Shulman (1987) disebut PCK (Pedagogical Content Knowledge). Dengan PCK, guru mengenali pengetahuan tertentu untuk mengajar. Pengetahuan itu integrasi antara isi/materi dan pedagogi menjadi suatu konsep tentang bagaimana topik, masalah, atau isu-isu tertentu disusun atau diwakili, dan diadaptasi sesuai kemampuan, dan minat murid yang bermacam-macam.

Pengetahuan materi/bahan ajar untuk mengajar merupakan kategori pengetahuan yang kemungkinan membedakan kepahaman seorang pakar bidang tertentu dengan seorang pengajar. Seorang pengajar akan mensintesis dua pengetahuan (materi dan pedagogi) dengan cara analogi, ilustrasi, contoh, penjelasan, demonstrasi, strategi dan memprediksi kemampuan serta kesulitan yang mungkin dialami murid-murid.

Ada beberapa cara agar guru memiliki PCK, yakni: melakukan refleksi setelah mengajar, wawancara/dialog dengan murid, diskusi dengan guru lain, kegiatan yang mendukung (seminar, PTK, kursus, masuk organisasi profesi, menulis di jurnal dan media massa). Hal ini penting mengingat guru bukan hanya harus memahami isi/materi ajar melainkan tujuan, sejarah dan kepentingan mata pelajaran tersebut dalam kehidupan.

Selanjutnya ketika teknologi informasi dan komunikasi berkembang dengan sangat cepat dan mulai memasuki sekolah dengan merata, dan anak-anak mulai terbiasa menggunakan teknologi informasi dan komunikasi dalam kesehariannya, sudah saatnya guru-guru mulai menerapkan teknologi informasi dan komunikasi dalam pembelajarannya. Akan tetapi mengintegrasikan teknologi informasi dan komunikasi dalam pembelajaran di kelas merupakan tantangan yang tidak mudah dihadapi.

Untuk menjawab tantangan tersebut, sebuah kerangka teoritis penting yang muncul saat ini dalam penggunaan teknologi informasi dan komunikasi oleh guru adalah Technological Pedagogical Content Knowledge (TPACK). Ide dari Technological Pedagogical Content Knowledge 
(TPACK) muncul secara formal pada jurnal pendidikan tahun 2003 dan mulai ramai diperbincangkan tahun 2005 yang awalnya disingkat TPCK namun berganti menjadi TPACK untuk memudahkan dalam pengucapannya (Chai, Koh, \& Tsai, 2013). Temuan penelitian yang relevan diperoleh pada tahun 2013 (Hartati, 2013) yakni PCK bagi mahasiswa S-2 Pendidikan Dasar dalam Rangka Implementasi Kurikulum 2013.

Technological Pedagogical Content Knowledge (TPACK) merupakan pengembangan dari Pedagogical Content Knowledge (PCK)-nya Shulman (1986). Technological Pedagogical Content Knowledge (TPACK) merupakan sebuah kerangka untuk mengintegrasikan teknologi dalam mengajar (Koehler, Mishra, Ackaoglu, \& Rosenberg, 2013). Koehler, Mishra, Ackaoglu, \& Rosenberg (2013) lebih jauh menjelaskan tiga kajian pengetahuan utama dalam Techonological Pedagogical Content Knowledge (TPACK) adalah Techonological Knowledge (TK), content knowledge (CK), dan pedagogical knowledge (PK) serta interaksi diantara setiap dua pengetahuan tersebut dan diantara semua pengetahuan tersebut.

Technological Knowledge (TK). Technological Knowledge meliputi pemahaman bagaimana menggunakan software dan hardware komputer, peralatan presentasi seperti dokumen presentasi, dan teknologi lainnya dalam konteks pendidikan. Technological Knowledge juga meliputi kemampuan untuk mengadaptasi dan mempelajari teknologi baru. Keberadaan kemampuan ini perlu di- miliki mengingat perkembangan dan perubahan teknologi terus menerus terjadi. Misalnya, perkembangan komputer yang terus menerus berubah dari mulai Personal Computer (PC) hingga notebook saat ini. Padahal komputer tersebut dapat digunakan untuk berbagai tugas pedagogis seperti penelitian, komunikasi dan lain-lain.

Content Knowledge mengarah kepada pengetahuan atau kekhususan disiplin ilmu atau materi pelajaran. Content Knowledge ini berbeda di tiap tingkatannya (contoh perbedaan di sekolah dasar dan sekolah menengah). Seorang guru diharapkan menguasai kemampuan ini untu mengajar. Content Knowledge juga penting karena kemampuan tersebut menentukan cara kekhasan berpikir dari disiplin ilmu tertentu pada setiap kajiannya.

Prinsip pembelajaran yang dapat dikembangkan pada abad 21 oleh guru dan siswa menurut Jennifer Nichols (dalam Daryanto: 2017) yaitu: (1) Instruction should de student -centered; (2) Education should be collaborative; (3) Learning have a context; dan (4) Schools should be integrated with society. Sejalan dengan pendapat Jennifer Nichols peneliti mengembangkan suatu model pembelajaran untuk mempersiapkan calon guru profesional yang ada pada Program Pendidikan Profesi Guru (PPG) Prajabatan yang dapat mengembangkan kualitas pembelajaran dan paradigma baru pendidikan dunia.

Pendidikan Profesi Guru (PPG) dalam kerangka profesionalisasi guru adalah pembentukan dan pengasahan kiat profesional 
secara berkelanjutan berupa latihan menerapkan perangkat utuh kompetensi akademik yang dipersyaratkan bagi guru secara kontekstual atau non rutin, dalam praktek nyata yang berlangsung dalam seting otentik. Dengan demikian keutuhan pendidikan guru terdiri atas pendidikan akademik guru dan pendidikan profesi guru, baik melalui pendidikan guru teritegrasi maupun pendidikan guru yang idealnya telah bersertifikat sebagai supervisor pendidikan profesi guru.

Program Pendidikan Profesi Guru (PPG) mensyaratkan pendidikan akademik yang relevan sebelumnya, karena didalam PPG para peserta didik pada dasarnya difasilitasi secara sistematis dan tersupervisi untuk menerapkan kompetensi akademik yang diperolehnya pada waktu menempuh program pendidikan akademik di jenjang S1. Dengan PPG para peserta diharapkan menguasai kompetensi profesional yang berujung pada pemberian gelar guru profesional. Salah satu keterampilan profesional guru adalah keterampilan menggunakan ICT dan keterampilan berpikir tingkat tinggi (KBTT). Kedua keterampilan ini dipandang sebagai keterampilan yang fundamental dalam menyongsong abad 21 (Henriksen, 2016).

Penelitian ini bertujuan menyusun dan menerapkan model TPACK bagi mahasiswa PPG-SD Prajabatan sebagai bekal menjadi pakar dan guru profesional di sekolah dasar. Secara umum yang dihasilkan dari penelitian ini diharapkan melahirkan lulusan yang memiliki karakterisik: (1) Mampu menunjukkan seperangkat kompetensi sesuai dengan standar yang berlaku; (2) Mampu bekerja dengan menerapkan prinsip-prinsip keilmuan dan teknologi dalam memberikan layanan seorang ahli; (3) Mematuhi kode etik profesi guru yang memintanya bertindak sesuai norma kepatutan; (4) Bekerja dengan penuh dedikasi; (5) Membuat keputusan secara mandiri maupun bersama-sama, (6) Menunjukkan akuntabilitas kinerjanya kepada pihak-pihak terkait, (7) Bekerja sama dengan sejawat dan pihak lain yang relevan, serta secara berkesinambungan mengembangkan diri baik secara mandiri maupun melalui asosiasi profesi. Secara khusus lulusan PPG-SD SM3T ini akan dapat menyusun silabus, RPP, media, dan evaluasi berdasarkan TPACK dan Kurikulum 2013.

\section{B. HASIL DAN PEMBAHASAN}

Penelitian ini menggunakan pendekatan kuantitaif dengan metode kuasi eksperimen dengan desain nonequivalent control group design. subjek pada penelitian ini, yaitu mahasiswa PPG SD Prajabatan tahun akademik 2018/2019. Jumlah sampel penelitian ini sebanyaj 42 mahasswa yang terdiri dari 21 kelas A dan 21 kelas B. Pada kelas B dijadikan kelas eksperimen dan kelas A dijadikan kelas kontrol. gambaran dari desain penelitian ini dapat dilihat pada gambar 1 sebagai berikut (Rusefeendi, 2010. Hlm. 53)

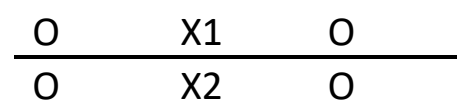

Gambar 1. Desain Kelompok Kontrol Nonequivalent.

Keterangan:

DOI:https://doi.org/10.17509/e.v18i2.15092 
$\mathrm{O}=$ hasil pretes atau postes

$\mathrm{X} 1=$ perlakuan pada kelompok eksperimen yang menerapkan TPACK berbasis Literasi dan Keterampilan berpikir tingkat tinggi

$\mathrm{X} 2=$ perlakuan pada kelompok kontrol yang menggunakan model pembelajaran konvensional.

Berikut ini pengujian terhadap data pretest kelas kontrol dan kelas eksperimen.

Tabel 1. Uji Normalitas

\begin{tabular}{|c|c|c|c|c|c|c|}
\hline & \multirow{2}{*}{\multicolumn{2}{|c|}{$\begin{array}{l}\text { Kolmogorov- } \\
\text { Smirnov }^{\mathrm{a}}\end{array}$}} & \multicolumn{4}{|c|}{ Shapiro-Wilk } \\
\hline & & & & & & \\
\hline & Statistic & Df & Sig. & Statistic & $\mathrm{df}$ & Sig \\
\hline pre- & .158 & 21 & .186 & .918 & 21 & .07 \\
\hline test_eksperimen & & & & & & 9 \\
\hline Pretest_kontrol & .228 & 21 & .006 & .918 & 21 & .08 \\
\hline & & & & & & 1 \\
\hline \multicolumn{7}{|c|}{ a. Lilliefors Significance Correc- } \\
\hline tion & & & & & & \\
\hline
\end{tabular}

Dari tabel diatas dapat dilihat bahwa uji Kolmogorov dan Shapiro-Wilk terhadap data menghasilkan signifikansi sebesar 0,079 dan 0.081 yang mana lebih besar dari nilai $=$ 0,05 . Dari analisis data ini dapat disimpulkan bahwa data pengukuran awal (pre test) dan berdistribusi normal. Karena data berdistribusi normal, langkah selanjutnya yang dilakukan adalah uji homogenitas. Hasil uji homogenitas data terlihat pada tabel berikut,

Tabel 2. Hasil Uji Homogenitas Pretest dan Postest

\begin{tabular}{rrrrrr}
\hline Levene Statistic & df1 & & df2 & \multicolumn{3}{c}{ Sig. } \\
\hline .261 & & 1 & 40 & .612 \\
\hline
\end{tabular}

Berdasarkan Tabel 2, diperoleh nilai signifikansi sebesar $0,612>=0,05$, sehingga dapat dikatakan bahwa varians data bersifat homogen. maka selanjutnya data diana- lisis dengan menggunakan uji $\mathrm{t}$ dengan rumusan hipotesis sebagai berikut:

$\mathrm{H} 0$ : tidak terdapat perbedaan kemampuan yang signifikan pengukuran awal (pre test) kelas kontrol dan kelas eksperimen.

H1 : terdapat perbedaan kemampuan yang signifikan pengukuran awal (pre test) kelas kontrol dan kelas eksperimen

Taraf signifikan yang digunakan adalah 0,05 dengan ketentuan uji, jika nilai t hitung lebih besar dari 0,05 maka H0 diterima, dan jika t hitung lebih kecil dari 0,05 maka $\mathrm{H} 1$ diterima. Dengan menggunakan software SPSS 16.0, diperoleh hasil uji perbandingan untuk pengukuran awal (pre test) kelas kontrol dan kelas eksperimen disajikan sebagai berikut:

Tabel 3. Hasil Uji Perbandingan Pengukuran Awal (Pretest) dan Pengukuran Akhir (Posttest) pada Kelas Eksperimen

Pada tabel output di atas diperoleh informasi bahwa nilai signifikansi untuk pen-

\begin{tabular}{cccc}
\hline$T$ & Df & $\begin{array}{c}\text { Sig }(2- \\
\text { tailed })\end{array}$ & Kesimpulan \\
\hline 0,334 & 1 & 0,566 & $\mathrm{H}_{0}$ diterima \\
\hline
\end{tabular}

gukuran awal (pre test) dan pengukuran akhir (post test) di kelas eksperimen sebesar 0,566 nilai tersebut lebih besar dari 0,05 sehingga dapat disimpulkan bahwa Ho diterima dan $\mathrm{H} 1$ ditolak. Artinya, tidak terdapat perbedaan kemampuan yang signifikan pengukuran awal (pre test) kelas kontrol dan kelas eksperimen.

Hasil pretest menunjukkan bahwa kemampuan awal kualitas pembelajaran maha-

DOI:https://doi.org/10.17509/e.v18i2.15092 
179 Technological Pedagogical Content Knowledge (TPACK) Dalam Rangka Peningkatan Kualitas Pembelajaran Mahasiswa PPG SD Prajabatan

siswa baik di kelas kontrol maupun eksperimen masuk dalam kategori kurang. Jadi kemampuan awal kualitas pembelajaran mahasiswa di kelas eksperimen dan kontrol tidak berbeda Hal ini menunjukkan hasil ujicoba penelitian akan objektif karena syarat pretest yang baik adalah tidak terdapat perbedaan signifikan pada kelas eksperimen dan kontrol (Arikunto, 2013).

Pengujian terhadap perbedaan peningkatan kemampuan kualitas pembelajaran antara kelas eksperimen dan kelas kontrol dilakukan dengan melakukan analisis terhadap data hasil skor N-gain pada kedua kelas.

Untuk melihat perbandingan analisis statistik deskriptif antara kelas kontrol dan kelas eksperimen, terlihat dari diagram berikut,

Tabel 4. Hasil Uji Normalitas N-Gain Kelas Eksperimen dan Kelas Kontrol

\begin{tabular}{cccccccc}
\hline & \multicolumn{3}{c}{$\begin{array}{c}\text { Kolmogorov- } \\
\text { Smirnov }\end{array}$} & \multicolumn{3}{c}{ Shapiro-Wilk } \\
& Statistic & df & Sig. & Statistic & Df & Sig. \\
\hline ngain_eksperimen & .135 & 21 & .200 & .939 & 21 & $\mathbf{. 1 8 5}$ \\
ngain_kontrol & .176 & 21 & .075 & .929 & 21 & $\mathbf{. 1 1 4}$ \\
\hline
\end{tabular}

Dari tabel diatas dapat dilihat bahwa uji Shapiro-Wilk terhadap data menghasilkan signifikansi sebesar 0,185 pada data eksperimen dan 0,114 pada data kontrol. Kedua hasil signifikansi ini bernilai lebih besar dari $=0,05$. Dari analisis data ini dapat disimpulkan bahwa data baik di kelas eksperimen maupun kontrol berdistribusi normal. Karena data berdistribusi normal, langkah selanjut- nya yang dilakukan adalah uji homogenitas. Hasil uji homogenitas data terlihat pada tabel berikut,

Tabel 5. Hasil Uji Homogenitas N-Gain

Kelas Eksperimen dan Kelas Kontrol

\begin{tabular}{l|l|l|l}
\hline Levene Statistic & df1 & df2 & Sig. \\
\hline 9.512 & 1 & 42 & .004 \\
\hline
\end{tabular}

Berdasarkan tabel di atas, terlihat bahwa diperoleh nilai signifikansi sebesar 0,004, yang mana signifikansi ini lebih kecil dari $=$ 0,05, sehingga dapat disimpulkan bahwa varians data bersifat tidak homogen. Setelah diketahui bahwa tidak homogen, maka selanjutnya data dianalisis dengan menggunakan uji t' dengan rumusan hipotesis sebagai berikut:

H0 : tidak terdapat perbedaan peningkatan yang signifikan kemampuan mahasiswa ppg yang menerapkan TPACK (kelas eksperimen) dengan yang tidak menerapkan TPACK (kelas kontrol)

H1 : terdapat perbedaan peningkatan yang sinifikan kemampuan mahasiswa ppg yang menerapkan TPACK (kelas eksperimen) dengan yang tidak menerapkan TPACK (kelas kontrol)

Taraf signifikan yang digunakan adalah 0,05 dengan ketentuan uji, jika nilai t hitung lebih besar dari 0,05 maka H0 diterima, dan jika t' hitung lebih kecil dari 0,05 maka $\mathrm{H1}$ diterima. Dengan menggunakan software SPSS 22, diperoleh hasil uji perbandingan sebagai berikut:

DOI:https://doi.org/10.17509/e.v18i2.15092 
Tabel 6. Hasil Uji Perbandingan Peningkatan Kemampuan Kolaborasi antara Kelas

\begin{tabular}{c|c|c|c}
\hline $\mathbf{t}^{\prime}$ & Df & $\begin{array}{c}\text { Sig (2- } \\
\text { tailed) }\end{array}$ & Kesimpulan \\
\hline 3.934 & 24.4 & 0,001 & $\mathrm{H}_{0}$ ditolak \\
\hline
\end{tabular}

Eksperimen dan Kelas Kontrol

Pada tabel output di atas diperoleh informasi bahwa nilai signifikansi yang dihasilkan dari uji perbandingan peningkatan kemampuan kualitas pembelajaran mahasiswa ppg antara kelas eksperimen dan kontrol adalah sebesar 0,001 . Nilai tersebut lebih besar dari 0,05 sehingga dapat disimpulkan bahwa Ho ditolak, H1 diterima. Artinya, terdapat perbedaan peningkatan yang signifikan kemampuan mahasiswa ppg yang menerapkan TPACK (kelas eksperimen) dengan yang tidak menerapkan TPACK (kelas kontrol).

Kualitas pembelajaran mahasiswa PPG dengan menerapkan TPACK berbasis website yang dapat di akses dengan mudah oleh mahasiswa dengan membuka laman www.tpack-sd.com mahasiswa dengan mudah mengunduh materi pembelajaran, mengunggah tugas, berdiskusi dengan sesame mahasiswa dengan membahas suatu topik pembelajaran, latihan soal dan tugastugas.

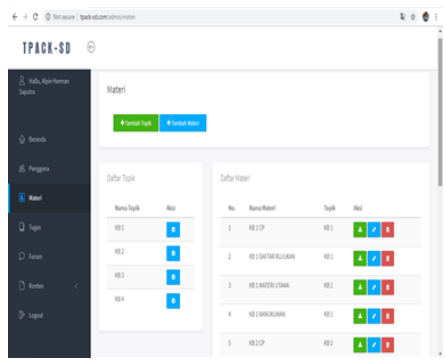

Gambar 2. Tampilan web tpacksd.com

No. SK Akreditasi Ristekdikti : 34/E/KPT/2018
Analisis data menunjukkan bahwa pembelajaran berbasis TPACK efektif dan signifikan serta menyenangkan bagi peserta PPG SD Prajabatan bersubsidi. Hal ini karena pembelajaran TPACK menggunakan WEB, ketika mahasiswa dapat belajar dimana dan kapan saja tidak bergantung adanya kelas. WEB memfasilitasi peserta untuk pendalaman materi sesuai kurikulum PPG dan kurikulum SD 2013. Di samping itu para peserta dapat mempelajari soal-soal UN dan melakukan diskusi atau tanya jawab pada halaman forum diskusi.

Analisis soal-soal dan Forum Diskusi diarahkan pada masalah-masalah yang mengacu pada keterampilan berpikir tingkat tinggi (KBTT/HOTS) hal ini penting dilatihkan karena sebagai guru SD profesional mesti memiliki keterampilan abad 21, antara lain TPACK dan KBTT (Henriksen, Mishra, Fisser (2016)

\section{SIMPULAN}

TPACK dan KBTT sangat penting bagi guru SD dan sebagai fondasi pembelajaran pada abad 21. Hasil analisis data menunjukan pembelajaran berbasis TPACK sangat signifikan dalam meningkatkan kualitas pembelajaran PPG SD Prajabatan UPI, sehingga hasil penelitian ini sesuai dengan tujuan penelitian yakni menyusun dan menerapkan model TPACK bagi mahasiswa PPG -SD Prajabatan sebagai bekal menjadi pakar dan guru profesional di sekolah dasar

Selain berbasis TPACK pembelajaran PPG SD Prajabatan UPI juga berbasis KBTT yang diberikan secara integratif dalam semua

DOI:https://doi.org/10.17509/e.v18i2.15092 
181 Technological Pedagogical Content Knowledge (TPACK) Dalam Rangka Peningkatan Kualitas Pembelajaran Mahasiswa PPG SD Prajabatan

mata kuliah terutama dalam Pendalaman Materi Bahasa dan Sastra Indonesia. Dari segi sikap, mahasiswa PPG SD Prajabatan UPI tampak lebih baik, menghayati perannya sebagai guru SD dan selalu semangat dan ceria ketika workshop di kelas-kelas PGSD. Penggunaan pembelajaran ICT dengan adanya WEB sangat mendukung dan mengefektifkan pembelajaran PPG SD Prajabatan.

Bagi pengelola, model pembelajaran TPACK dan KBTT selayaknya digunakan bagi PPG prajabatan dan PPG Dalam jabatan. Bagi Mahasiswa PPG SD Prajabatan agar senantiasa memanfaatkan model TPACK dan KBTT ketika mengajar di SD. Disamping itu agar senantiasa membuka WEB tpack-sd.com untuk peningkatan mengajar dan penyegaran ilmunya.

\section{DAFTAR PUSTAKA}

Arikunto, S. (2013). Dasar-dasar Evaluasi Pendidikan. Jakarta: PT. Bumi Aksara

Chai, C. -S., Koh, J. H. -L., \& Tsai, C. -C. (2013). A Review of Techonological Pedagogical Content Knowledge. Educational Techonological \& Society, 16 (2), 31-51.

Daryanto dan Karim, S. (2017). Pembelajaran Abad 21. Yogyakarta: Penerbit Gava Media.

Koehler, M. J., Mishra, P., Ackaoglu, M.,\&Rosenberg, J. M. (2013). The Techonological Pedagogical Content Knowledge Framework for Teachers and Teacher Educators. Commonwealth Educational Media Centre for Asia Teacher. No. 9702. Jan 14,1997.
Muhali, M. (2018). Arah Pengembangan Pendidikan Masa Kini Menurut Perspektif Revolusi Industri 4.0. In Prosiding Seminar Nasional Lembaga Penelitian dan Pendidikan (LPP) Mandala.

Efendy, R. (2010). Metode Penelitian. Bandung: Rafika.

Seknun, M. Y. (2014). Telaah kritis terhadap perencanaan dalam proses pembelajaran. Lentera Pendidikan: Jurnal Ilmu Tarbiyah dan Keguruan, 17(1), 80-91.

Shulman, L.S. (1986). Those who understand: Knowledge Growth in Teaching. Educational Researcher, 15/2, 414.

Shulman, L.S. (1987). Knowledge and Teaching: Foundations of New Reform: Harvard Educational Review. $57 / 1,1-22$.

Hartati, T. dkk. (2013). Road Map Penelitian PPG-SD Prodi PGSD. Bandung : PGSD.

Henriksen, D., Mishra, P., \& Fisser, P. (2016). Infusing Creativity and Technology in 21 st Century Education: A Systemic View of Change. Journal of Educational Technology and Society. 19(3), 27-37.

DOI:https://doi.org/10.17509/e.v18i2.15092 